\title{
Los capiteles del claustro de San Pedro el Viejo de Huesca: nuevas aportaciones a partir del examen de su restauración
}

\author{
Maria-Laura Figueras La Peruta \\ Universidad Autónoma de Barcelona. Departamento de Arte.
}

\begin{abstract}
RESUMEN
El monasterio de San Pedro el Viejo de Huesca conserva en su claustro románico un extraordinario legado escultórico, plasmado principalmente en los capiteles que conforman las cuatro galerías. El conjunto fue alterado a causa de las reformas efectuadas hacia 1890. Antes de valorar aspectos artísticos, se ha creído imprescindible revisar el estado actual de los capiteles, que hasta ahora no había sido estudiado en detalle. A través de la comparación entre las labras y diversas fuentes textuales y gráficas (algunas inéditas), se ha constatado que tras la restauración y posterior recolocación de las tallas se cambió la disposición y configuración de algunas piezas. En este artículo se intenta reconstruir la topografia e iconografia de la arquería claustral original.
\end{abstract}

Palabras clave: Restauración; Escultura Románica; Capiteles; Claustro.

\section{The capitals of San Pedro el Viejo de Huesca cloister: new questions regarding its restoration}

\begin{abstract}
The Romanesque monastery of San Pedro el Viejo in the city of Huesca (today a parish church) preserve in the cloister an extraordinary sculptural heritage, depicted chiefly in the capitals that conform their four galleries. The artistic set was altered on account of the reforms performed toward 1890. Before assessing artistic aspects, it was thought indispensable to revise the current state of the capitals, which had hitherto not been studied in detail. Through the comparison between sculpture pieces and professional sources (some unpublished), has been verified that after the restoration and subsequent relocation of the pieces, the emplacement and configuration of some of them was altered. This article presents a proposal on the original design of the cloister arcade, interpreted with relation to its particular topography and iconography.
\end{abstract}

Keywords: Restoration; Romanesque Sculpture; Capitals; Cloister.

$$
\begin{array}{r}
\text { ¿Mas es acaso el claustro que hoy admiramos } \\
\text { el mismo que fue testigo mudo } \\
\text { de las penitencias del rey monje?, } \\
\text { Ricardo del Arco, 1914.* }
\end{array}
$$

* Desde el recuerdo y el agradecimiento, dedico este trabajo a la profesora Marisa Melero. Doy también las gracias a las bibliotecarias del Instituto de Estudios Altoaragoneses de Huesca por su entrañable ayuda. Este artículo es el resultado de un complejo camino, suma de equívocos e inquietudes vadeados gracias a las precisiones y correcciones de otras voces y otras miradas. Al particular, deseaba reconocer al profesor Carles Mancho sus enseñanzas sobre la crítica arqueológica que requiere toda investigación románica; y muy especialmente, la tutoría del profesor Daniel Rico, quien solícito en sus rigurosas indicaciones me ha permitido incursionar en el ámbito del claustro de San Pedro desde otra perspectiva, pudiendo demostrar así la importante necesidad del estudio pluridisciplinar en la Historia del Arte. 


\section{La renovación de una obra}

El claustro románico de San Pedro el Viejo de Huesca ha gozado de un interés parcial por parte de la historiografía, aunque estemos probablemente ante una obra que merecería tratarse de un modo más completo por tres razones significativas $^{1}$. En primer lugar, se han abierto vías de estudio sobre el cenobio que revelan un legado artístico con fuertes implicaciones litúrgicas y funerarias, a la par que un verdadero organismo monacal donde se materializó la realidad de un contexto histórico particular ${ }^{2}$. En segundo lugar, se suma la atención que actualmente motivan los claustros como objeto de examen interdisciplinar desde una perspectiva histórico-artística e incluso religiosa, social, política o económica ${ }^{3}$. Por último, no se ha analizado correctamente la restauración de 1890 que desvirtuó radicalmente el conjunto y sobre todo su testimonio más querido, los capiteles figurativos e historiados de las galerías. Quedan por definir cuestiones de la mayor relevancia, pero ninguna podrá abordarse con la debida seriedad si no se esclarece en primera instancia el alcance de la restauración decimonónica. Mi propósito en este artículo es revisar dichas reformas con el objeto de reconstruir en la medida de lo posible la configuración del claustro original.

En torno al siglo XIX, una relación de hechos circunstanciales en San Pedro había originado un deterioro y abandono tales, que instituciones y personajes comprometidos con el patrimonio adujeron la urgente necesidad de salvarlo de la ruina y consiguieron de este modo poner en marcha su reparación. En lo que atañe al claustro, en 1886 la decisión del primer arquitecto Juan Nicolau fue consolidar los muros perimetrales de los pasillos y demoler los macizos entre las arquerías. Unos años después, Patricio Bolomburu y Ricardo Magdalena fueron quienes dirigieron las obras de desmonte y recolocación de las labras, sustituyendo algunas por copias $^{4}$.

1 Sería prudente advertir que Duran Gudiol ya expresaba en 1978 la urgencia de confeccionar monografías correspondientes a monasterios, abadías y conventos aragoneses; UBIETO ARTETA, Agustín (coord.), Estado actual de los estudios sobre Aragón: actas de las I Jornadas, Teruel, Universidad de Zaragoza, 1978, p. 720. Me gustaría mencionar que así lo he adoptado respecto a San Pedro en mi propuesta de tesis en curso.

2 BALAGUER, Federico, Un monasterio medieval. San Pedro el Viejo, Huesca, Museo Arqueológico Provincial, 1946; CROZET, René, "Recherches sur la sculpture romane en Navarre et en Aragon. Sur les traces d'un sculpteur", en Cahiers de Civilisation Médiévale, XI, 1, 1968, pp. 41-57; MELERO MONEO, Marisa, "El llamado taller de San Juan de la Peña, problemas planteados y nuevas teorías", en Locus Amoenus, 1, 1995, pp. 47-60; RICO CAMPS, Daniel, "El claustro de San Pedro el Viejo de Huesca: Pascua, Bautismo y Reconquista", en Locus Amoenus, 7, 2004, pp. 73-97.

3 Pongamos por caso libros recientes y colectivos como el coordinado en Alemania por KLEIN, Peter (ed.), The Medieval cloister, Regensburg, Steiner, 2004, o en España por YARZA LUACES, Joaquín, BOTO VARELA, Gerardo (eds.), Claustros románicos hispanos, León, Edilesa, 2003.

4 En las siguientes páginas veremos que muchas piezas fueron entonces cambiadas de lugar e incluso modificadas a nivel iconográfico. Los factores que justificaron las reformas se pueden resumir en tres puntos. Por un lado, las circunstancias políticas favorecieron durante algunos siglos las construcciones en el claustro pero alteraron estructuras medievales. Por otro, los cambios urbanísticos y procesos desamortizadores en la ciudad decimonónica perjudicaron ostensiblemente el edificio. Finalmente, en lo que respecta a la escultura, 
Las fuentes de este trabajo las he obtenido en parte del libro de M. C. Fontana, La Iglesia de San Pedro el Viejo y su entorno: historia de las actuaciones y propuestas del siglo XIX en el marco de la restauración monumental, (Huesca 2003), que trata de la restauración desde una perspectiva más bien arquitectónica y urbanística. Por otra parte, he utilizado algunas fuentes inéditas o poco atendidas. Con todo este material, mi discurso consiste en comparar sistemáticamente los capiteles situados en el claustro actual con los originales y copias conservados en el Museo Provincial de Huesca, utilizando distintos planos, memorias, crónicas y fotografías de tiempos de la restauración ${ }^{5}$.

También querría mencionar, sin intención de adentrarme en aspectos que no corresponden al propósito de este trabajo, que la realidad románica de San Pedro se perdió ya antes de la restauración del XIX. Por ejemplo, como pasó en tantos otros conjuntos, el recinto oscense debió adaptarse a nuevas necesidades de espacio y por tanto se levantaron construcciones que desdibujaron las creaciones medievales; o inclusive, la precariedad con que vivieron los clérigos en muchas épocas no podía mantener la conservación de la obra tal como la entenderíamos hoy en día. No obstante, la identidad románica del claustro fue trágicamente descuidada no sólo por una corriente historicista, sino por parte de una dinámica de grupo contemporánea y posterior, en la cual, cuanto más se observa la obra, más se percibe una apatía y desamparo inquietantes ${ }^{6}$.

no hay que olvidar que nos hallamos además ante una obra construida con la piedra de su entorno, una roca arenisca de fácil erosión que privó a la mayoría de los capiteles de su forma original. Otros motivos se observan en la insistencia de Vicente Carderera que exponía la falta de presupuesto que se destinaba al claustro de San Pedro y el riesgo que se corría de que se vendieran piezas a museos extranjeros; CARDERERA, Vicente, "Oficio en el que se exponen las causas que impiden a la Comisión de Monumentos de Huesca cumplir sus deberes, en contestación a una comunicación de la Academia para que dicha Comisión dé cuenta de los descubrimientos de interés histórico de la provincia", Legajos de la Comisión de Monumentos de Huesca, CAH/9/7957/4(1), (1883/04/21).

5 La información obtenida hasta el momento no supone que todos los interrogantes sobre la dinámica restauradora de San Pedro estén resueltos. Subsisten algunas incongruencias entre las memorias narradas por los tres arquitectos que se sucedieron, entre cotejos de los planos, de las fotografías, de los dibujos y un largo etcétera. Incluso hay fuentes que se sabe existieron pero hoy en día desconocemos dónde se encuentran. De ahí que la investigación no esté cerrada, y confío que si se completan ciertos vacíos documentales alcanzaremos una mejor interpretación del conjunto medieval.

${ }^{6}$ La institución de San Pedro se encontraba en una situación de vacío normativo, los ingresos de los clérigos servían solamente para la subsistencia y la política cultural no resguardaba el patrimonio artístico del monasterio. La Real Academia de Bellas Artes de San Fernando pide a la Comisión de Monumentos de Huesca que conserve los bienes extraídos de la iglesia de San Pedro, pero ésta se defiende diciendo "que no hay fondos, que hace dos años que San Pedro fue declarado en ruinas y que nadie ha hecho nada"; "Intenciones de restauración de San Pedro el Viejo", Real Academia de Bellas Artes de San Fernando, sign. 2-48-6, (1856-04-18). Por ejemplo, fue la misma Academia de San Fernando que creyó "preferible su derribo para reedificarlo por completo [...]"; BOLOMBURU, Patricio, "Memoria del primer presupuesto adicional de las obras de la iglesia y claustro de San Pedro el Viejo", Archivo General de la Administración, AGA, 31/8060, (1888-04-30), p. 33. 


\section{La re-visión de un claustro}

Los 38 capiteles que hoy vemos en las arquerías del claustro fueron recolocados por el arquitecto Ricardo Magdalena hacia 1893 en la última etapa de la restauración ${ }^{7}$. Según el plano publicado en Aragon Roman, de las 38 piezas, 18 son originales y 20 son copias $^{8}$. Como se verá más adelante, la disposición actual de estas piezas y algunas de sus escenas no parecen respetar fielmente el estado original. La distinción que viene haciéndose entre copias y originales tampoco es del todo correcta. En las siguientes páginas se mostrarán en los capiteles recolocados ciertas alteraciones que no se habían percibido hasta el momento, de lo que se derivará una "nueva visión" del claustro románico.

Previamente, en los dos primeros puntos de este apartado, se mencionarán las fuentes y el material que servirán para constatar la ubicación y la iconografía de cada una de las piezas antes de su restauración y recolocación. En primer lugar, dado que en la reforma de los capiteles intervinieron diferentes arquitectos, se detallan los proyectos sucesivos y complementarios ${ }^{9}$. Esto informa de distintas actuaciones en las cuatro galerías, de manera que en segundo lugar se indicará la documentación específica para el estudio de cada una de ellas. Finalmente, a través del examen de todo lo anterior, se presenta una propuesta nueva para seis grupos de capiteles: originales cambiados o no de posición, copias fieles iconográficamente a los originales cambiadas o no de posición, y copias desacordes con los originales cuyas modificaciones iconográficas he podido o no detectar. Cada uno de estos grupos se indica en la fig. 1 con un color distintivo.

Antes de empezar, es importante asimismo explicar el sentido que tienen las tres cifras que acompañan a cada capitel en dicha planta: los números en letra redonda situados en el lado interno de la misma se corresponden con los

7 MAGDALENA, Ricardo, "Memoria del segundo presupuesto adicional para la terminación de las obras de la iglesia de San Pedro el Viejo", Archivo General de la Administración, AGA 31/8060, (1890-1204), en FONTANA CALVO, María Celia (2003), op. cit., p. 124. Vida de Jesús: 1-21; ciclo del Mal: 22-38 (fig. 1). Desde la publicación del libro de Aynsa, el programa iconográfico del claustro ya se entiende como una división de los 38 capiteles entre "historias de la Sagrada Escritura, y otras labores hechas a lo grotesco", tal como se muestra a grandes rasgos hoy en día; AYNSA Y YRIARTE DE, Francisco Diego, Fundación, excelencias, grandezas, y cosas memorables de la antiquísima ciudad de Huesca, así en lo temporal, como en lo espiritual, divididas en cinco Libros, cuyos sugetos dirá la página siguiente (ed. facs. 1987), III, Huesca, Ayuntamiento, 1619, p. 541. En el apéndice de este artículo, la columna A resume la iconografía y situación actuales de los capiteles, y la B, mi aportación.

8 CANELLAS LÓPEZ, Ángel, Aragon Roman, Yonne, Zodiaque, 1971, p. 343 (marcados en negro los originales, copias en color blanco). El plano se basa en la observación directa del claustro actual y en lo descrito por CROZET, René (1968), op. cit., pp. 41-57. De todas maneras, en Crozet no se entiende en ciertos casos qué interpreta como originales y qué como copias.

9 Las memorias redactadas fueron dadas a conocer por Ascensión Hernández, quien recopiló un valiosísimo material destacando la labor de Ricardo Magdalena, pero además la de Patricio Bolomburu, a quien no se le atribuían grandes trabajos en San Pedro, HERNÁNDEZ MARTÍNEZ, Ascensión, "La restauración monumental en el siglo XIX: Las intervenciones de Ricardo Magdalena", en Artigrama, 6-7, 1989-1999, pp. 345-369. Sin embargo, las intervenciones ejecutadas por los arquitectos en los capiteles no habían sido revisadas hasta este trabajo. 


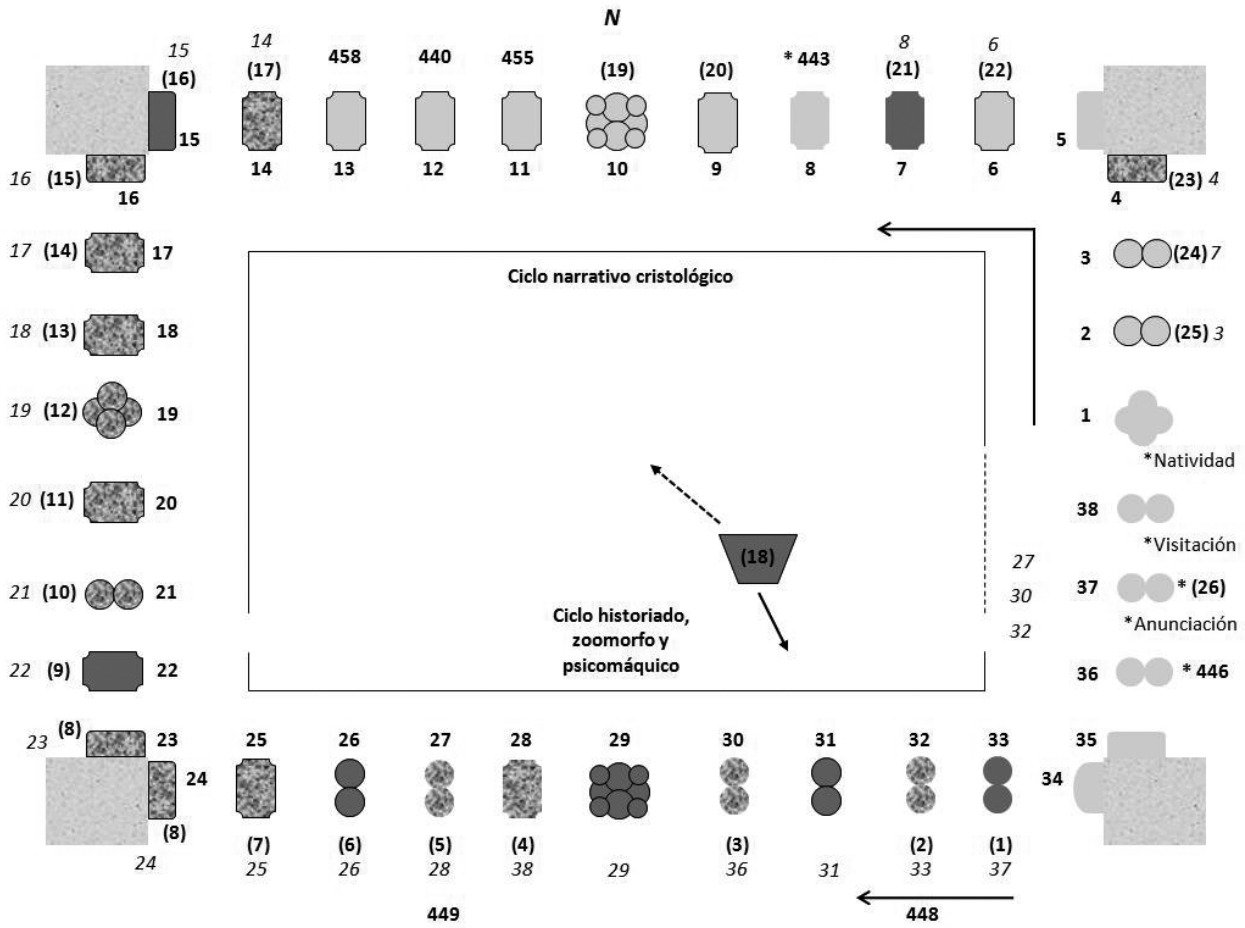

Fig. 1. Planta del claustro de San Pedro el Viejo, Huesca, finales del siglo XII, M. L. Figueras La Peruta.

de la tabla A del apéndice y señalan la ubicación actual de las labras (se trata, de hecho, del sistema de numeración utilizado en el volumen Aragon Roman de la Zodiaque); los números en letra cursiva del lado exterior sitúan esos mismos capiteles (o, mejor dicho, sus versiones originales) en la posición que tuvieron en el claustro antes de la restauración y se corresponden con los de la tabla B; finalmente, las cifras entre paréntesis indican la numeración utilizada por los restauradores tal y como revela un precioso conjunto de fotografías del que hablaré en seguida. En el cuerpo del artículo utilizaré las mismas distinciones tipográficas que en el plano.

\section{Intervención de los arquitectos}

La restauración de los capiteles fue realizada entre 1886 y 1893. Tres arquitectos se sucedieron en la dirección de las obras, aunque sólo los dos últimos llevaron a cabo tareas sistemáticas de restauración.

- Juan Nicolau (1886-1888):

* Se limitó a tareas de contención de las estructuras ruinosas que afectaban la estabilidad de las arquerías por las fuerzas infringidas sobre ellas. 
* A pesar de no actuar finalmente en las reformas, tenía la intención de respetar la configuración de los capiteles ${ }^{10}$.

* Probablemente es quien numera los capiteles de las crujías sur y oeste previendo no perder el orden al desmontarlos ${ }^{11}$. Las primeras arquerías en demolerse para rehacer estructuras en ruinas fueron las pandas meridional y occidental, ya que las otras dos comportaban reformas más complejas ${ }^{12}$.

\section{- Patricio Bolomburu (1888-1890):}

* No respeta la restauración prevista por Nicolau ya que decide modificar ciertas piezas para mejorar la iconografía ${ }^{13}$.

* Encarga fotografías generales de la galería meridional y occidental ${ }^{14}$ y fotografías individuales de 28 capiteles con una numeración en el fuste ${ }^{15}$.

10 "Deben ser objeto de los mayores cuidados, a fin de ejecutar su reparación sin que se resienta su primitivo carácter"; NICOLAU, Juan, "Memoria descriptiva referente á las obras de consolidación y reconstrucción que deben llevarse á cabo en la Iglesia de San Pedro el Viejo de la Ciudad de Huesca”, AGA, 31/8059, (188604-03), p. 21.

11 "Tanto en las columnas como en los demás detalles propios, sólo de la época que pretendemos recordar, se deberá tener especial cuidado en seguir los pensamientos generales dominantes en la variedad de detalles que enriquecen los claustros, origen principal de todos nuestros imperfectos trabajos", Ibid.

12 "Hállanse las galerias origen de estos claustros por variadas y caprichosas columnitas, dispuestas en grupos de á cuatro unas, de á dos otras y aisladas en su mayor parte [...]. Los arcos [...] de medio punto [...] y diversos capiteles bizantinos que los coronan, habiéndose cubierto partes del mérito artístico de estos capiteles con los macizos ó rellenos llevados a cabo en 32 de los 34 arcos que constituyen los claustros actuales, dejando solo unos agujeros circulares [...] para dar paso á la luz [...]; Ibid., p. 21. Estos macizados entre las arquerías que malograron irremediablemente la forma de los capiteles, se retiraron primero de la crujía sur. En la banda occidental antes de desmontarlos se debía consolidar el muro del pasillo por empujes de las casas vecinas. En el lado norte, era necesario quitar los "cuatro anti-artísticos estribos" que servían de apoyo a esa arquería; Ibid., p. 23. La parte este, y más malograda, fue la última en trabajarse: "El aspecto del claustro tercero mirado por el jardín [...] se ve que para emplazar la escalera y cuerpo saliente X, fue preciso destruir cuatro arcos de los que componían la galería primitiva"; Ibid., pp. 15-16.

13 La Comisión de los Monumentos de Huesca nombró en 1889 al otro arquitecto provincial Patricio, Bolomburu, que no respetó las propuestas de Nicolau: $c f$. FONTANA CALVO, María Celia (2003), op. cit., p. 56. "Sustitución de basas y columnas de gran número de sus arcadas y reparación de estatuas y capiteles, construyendo de nuevo aquellos cuyos trazos se han perdido por completo"; BOLOMBURU, Patricio (1888), op. cit., p. 35.

14 "Obras de restauración de la Iglesia de San Pedro el Viejo de Huesca. Fotografías, Galería sur y oeste, Hojas No 6-7”, (AGA, 31/8060, 1888). NAVAL, A., NAVAL, J., Huesca. Siglo XVIII, Zaragoza, Publicaciones Cajas de Ahorros de Zaragoza, Aragón y Rioja, 1978, editaron la galería sur en un formato pequeño sin que hasta el momento se advirtiesen los cambios que se verán más adelante.

15 "Se tuvo el buen acuerdo de fotografiar los diferentes elementos de la fábrica"; BOLOMBURU, Patricio "Memoria...", (1888), op. cit., p. 35-36. No aporto todos los ejemplos de cada fotografía individual con la numeración; dichos documentos se pueden consultar en BOLUMBURU, Patricio, "Obras..." (1888), op. cit., Hojas $\mathrm{N}^{\mathrm{o}} 12-35$, y en la Real Academia de Bellas Artes de San Fernando, aunque algunas de ellas también están en el Museo Provincial de Huesca. 
* Desmonta los capiteles de las cuatro galerías ${ }^{16}$, pero antes acaba seguramente la numeración de las piezas en las pandas norte y este, dejando algunas de las mismas sin numerar porque probablemente no tenía previsto recolocarlas ${ }^{17}$.

* Restaura capiteles que habían perdido toda o parte de su iconografía, creando nuevas piezas a partir de los originales, seguramente con la técnica escultórica de copia por puntos, o limitándose a modificar algunas de sus caras: $16,17,18,19,20,21,28,33,36,38^{18}$. Y otros que no están hoy en el claustro: posiciones $9,11,12,13,14,37^{19}$.

- Ricardo Magdalena (1890-1893):

* Asume el final de la restauración ${ }^{20}$.

${ }^{16}$ En su presupuesto, apunta "Capiteles y columnas. Desmonte de los cuatro claustros"; BOLOMBURU, Patricio, "Presupuesto adicional para la terminación de las obras de la Iglesia y Claustros de San Pedro el Viejo", Archivo General de la Administración, AGA, 31/8060, 1888. Por tanto, Nicolau no llegó a desmontarlos. Asimismo, después de escribir estos presupuestos, relata en las memorias que los capiteles estaban "en el estado de mayor seguridad, pero más frío, en que ahora se encuentran"; BOLOMBURU, Patricio, "Memoria..." (1888), op. cit., p. 35. Por último, fotografías datadas en 1888 demuestran que los capiteles se alzaban aún sobre las arquerías.

${ }_{17}$ Es importante subrayar que Bolomburu conoció de primera mano la ubicación e iconografía del claustro original, y por eso se debe tener en cuenta que aunque decidió copiar algunos capiteles, existe una gran seguridad de que lo hiciera guardando fidelidad al claustro original "que humilde y austero muestra en la tosquedad de sus columnas y capiteles la fisonomía fiel y exacta de la época en que fue construido"; apud FONTANA CALVO, María Celia (2003), op cit., p. 116.

18 "Es inútil advertir el prolijo cuidado con que se han de ejecutar estas obras eminentemente artísticas, para las que se procurará elegir materiales de clase análoga, dándoles formas idénticas a las existentes que sirven de modelos, a fin de que la restauración no modifique en nada el primitivo carácter", "[...] construyendo de nuevo los capiteles cuyos trazos se han perdido por completo". Y lo justifica diciendo que las fotografías tomadas servirán para "demostrar así la filiación de las composiciones reproducidas en los elementos actuales"; Ibid., p. 117. Además en su presupuesto escribe: "Esculturas. En capiteles restaurados en dos de sus caras. En capiteles restaurados en sus cuatro caras. En capiteles nuevos para columnas sencillas. En capiteles nuevos para columnas dobles"; BOLOMBURU, Patricio, "Presupuesto..." (1888), op. cit., p. 2.

19 Hasta el momento no se había advertido de tal detalle, sin embargo Crozet se cuestiona en 1968 la originalidad de los capiteles 6 y 28; CROZET, René (1968), op. cit., pp. 45-46. Convendría mencionar también que Ricardo Del Arco, en 1914, se lamenta de que "sólo tres o cuatro capiteles son auténticos, sin adición alguna. Hay unos doce desfigurados por la restauración, y los demás son completamente nuevos"; ARCO, Ricardo del, "La escultura románica en el claustro de la iglesia de San Pedro el Viejo", en Arte Aragonés, I, n 8, 1914, p. 132.

20 A partir de 1890, un cambio en el Reglamento de Construcciones Civiles dio por concluida la intervención de los arquitectos provinciales en San Pedro e introdujo por el contrario a un arquitecto regional, Ricardo Magdalena, uno de los profesionales más prestigiosos de su tiempo. Éste desarrollaría sin interferencias los postulados violletianos, para entonces ampliamente conocidos por él pero no aplicados. No en vano, San Pedro el Viejo fue el primer monumento nacional que restauró; ARCO, Ricardo del, Reseña de las tareas de la Comisión provincial de los monumentos históricos y artísticos de Huesca, Huesca, Museo Provincial de Huesca, p. 40; FONTANA, María Celia (2003), op. cit., p. 62. Conoció las teorías del arquitecto francés no sólo a través de las publicaciones nacionales e internacionales que recibía el Casino de Zaragoza, sino directamente por los libros que encargó en 1882 para la oficina de Arquitectura del Ayuntamiento de Zaragoza; HERNÁNDEZ MARTÍNEZ, Ascensión (1989), op. cit., p. 353. 
* Plantea la recolocación de 22 capiteles pertenecientes al Nuevo Testamento y el resto, de "vicios y virtudes" 21.

* Reconstruye capiteles según la técnica del vaciado en yeso: posiciones 1 , 2, 3, 4, 5, mitad del 6 (?), 7, 9, 10, 11, 12, 13, 14, 23, 24, 25, 27, 30, 32, 34, $35^{22}$.

* Recoloca las cuatro arquerías de capiteles sobre fustes modernos, perdiéndose así la numeración originaria ${ }^{23}$.

\section{Relación de fuentes por galerías}

El presente trabajo parte del análisis meticuloso de una fotografía tomada en 1888 por encargo de Bolomburu, poco antes de que se desmontasen las cuatro galerías claustrales (fig. 2) ${ }^{24}$. En ella se distingue buena parte de la crujía meridional vista desde el suroeste y se advierte que el centauro que actualmente ocupa la posición 28, en la fotografía se encuentra situado en la posición número 27. En cambio, su vecino 26, en el que un hombre ataca con espada a un ser monstruoso, ocupa ese mismo lugar en la fotografía anterior a la restauración y también en el claustro actual. Estamos, por lo tanto, ante un ejemplo clarísimo de que en la reconstrucción decimonónica de las arquerías, Ricardo Magdalena unas veces respetó la ubicación original de las labras y otras veces $\mathrm{no}^{25}$.

21 "Hemos conseguido descifrar los dos pensamientos que predominan en las artísticas galerías de estos claustros. De los detenidos estudios llevados a cabo hemos podido averiguar que en los 22 capiteles correspondientes a las galerías $1^{\mathrm{a}}$ y $2^{\mathrm{a}}$ y mitad de la $3^{\mathrm{a}}$ se describe toda la historia sagrada del Nuevo Testamento, habiendo llegado hasta nosotros perfectamente conservados algunos capiteles y numerosas figuras, y que en el resto de la galería $3^{\mathrm{a}}$ y en la $4^{\mathrm{a}}$ se representan alegorías de los vicios y virtudes"; MAGDALENA, Ricardo (1890), op . cit., p. 124. La declaración de Magdalena no es concluyente porque el arquitecto describe unas piezas que ya no se encontraban dispuestas en las arquerías.

22 "Por la índole artística del trabajo, no creemos poder llevar a efecto con buen éxito la restauración, sin proceder antes a la composición de los motivos que faltan para completar, hacer después los modelos en barro y correspondientes vaciados en yeso [...]"; ibid., en FONTANA CALVO, María Celia (2003), op. cit., p. 124. Parece ser que las copias de esta etapa fueron hechas por encargo del arquitecto Ricardo Magdalena al escultor zaragozano D. Mariano García Ocaña, que "por entonces dio principio la restauración del templo de San Pedro el Viejo de Huesca, tomando á su cargo la modelación de los capiteles y otras obras.”; GARCÍA CIPRÉS, Gregorio, "San Pedro el Viejo (monumento nacional)”, en Linajes de Aragón, VII, 20, 1916, p. 358360 .

23 La única prueba de la que disponemos para constatar que Magdalena es el encargado de distribuir los 38 capiteles tal como los vemos hoy en día es una aclaración escueta en una de sus memorias, pudiendo sólo intuir las fuentes que utilizó para ejecutar esa distribución; "A fin de no interrumpir la marcha de las obras [...]”, apud FONTANA CALVO, María Celia (2003), op. cit., p. 124.

${ }^{24}$ No me consta que esta fotografía haya sido analizada antes de este trabajo, como de hecho ocurre con la mayoría que se utilizan en él. Se publica como grabado en De fotografias, "La Ilustración Española y Americana", n XV, abril 1899, p. 240.

25 Me permito recordar al lector que en el plano de la fig. 1 señalo la posición actual de los capiteles con la numeración en letra redonda y mi propuesta de disposición original con la numeración en cursiva. 


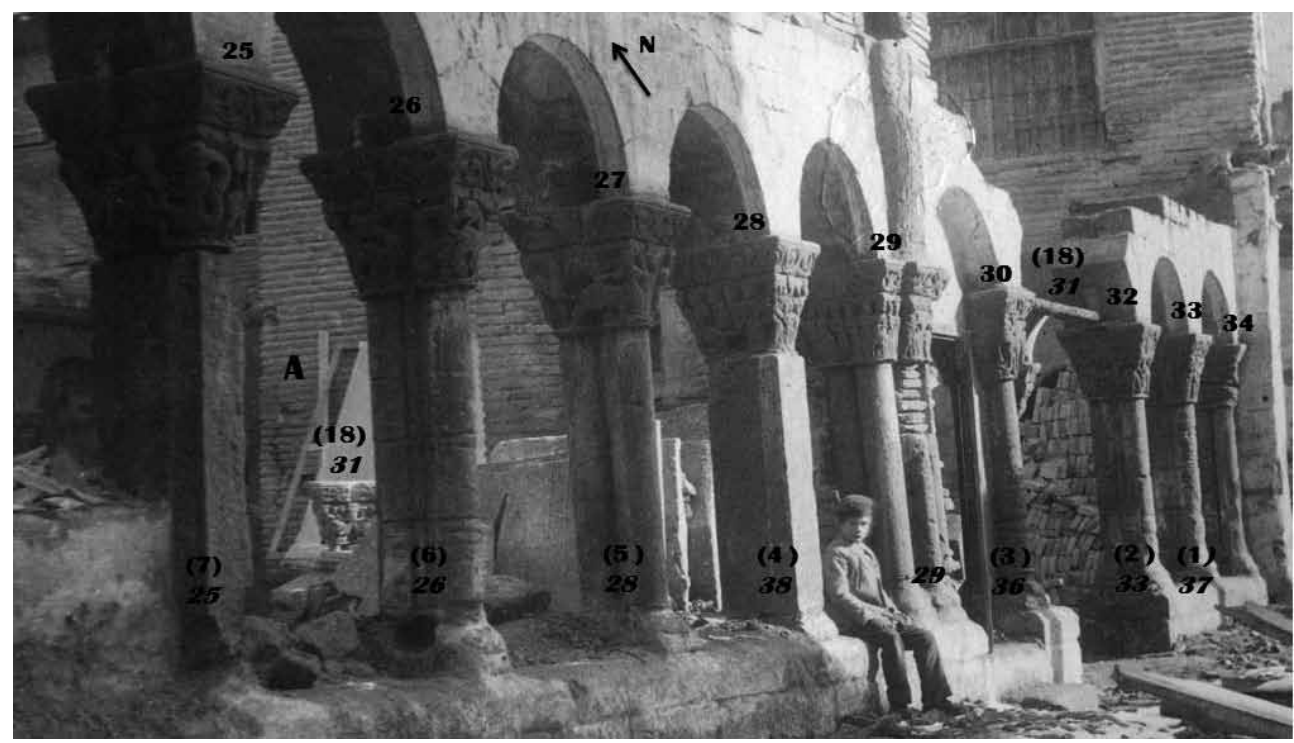

Fig. 2. Galería sur del claustro de San Pedro el Viejo, Huesca, AGA 31-8060 Hoja nº 6 (1888).

Además de esta reveladora fotografía y otra semejante de la galería occidental, conservamos fotos de veintiocho capiteles realizadas en 1888 por encargo también de Patricio Bolomburu. En veintiséis de ellas se distingue un número de identificación localizado en el fuste (fig. 1, dígitos entre paréntesis; véanse dos ejemplos en la fig. 3, recuadro "5", y fig. 4, recuadro "20"). El cotejo de las fuentes permite asegurar que esta nueva numeración se ordenaba tal y como muestran las cifras entre paréntesis de la fig. 1: a partir de la posición actual 33 y siguiendo el orden de las saetillas del reloj. Bastarán unos pocos datos para demostrarlo. Fijémonos que la fotografía general de la crujía sur (fig. 2) muestra que el capitel que hoy ocupa la posición 37 , antes de la restauración se situaba en la ubicación 33 (fig. 1, capitel 33 interno - 37 externo); de la misma forma, la foto general muestra el capitel 33 en la posición del actual 32. Puesto que los fustes de dichas labras tienen en las fotos de 1888 los números (1) y (2) respectivamente, está claro que la numeración de Bolomburu se ordenaba según acabo de indicar y, más importante aún, que los restauradores no la respetaron en el momento de colocar las cestas.

A partir de las fotos generales (sur y oeste) e individuales (1)-(16) (fig. 1), se verifica gráficamente, y a su vez se esclarece, el lugar y la iconografía de los capiteles meridionales y occidentales antes de la restauración (diferenciando copias de originales). En las pandas norte y este, las revisiones de las piezas (17)-(26) no permiten conclusiones tan claras. Por un lado, no contamos con foto general de 1888 que nos brinde una panorámica de la ubicación de cada capitel, y por otro, las fotos individuales antiguas muestran algunos capiteles en muy mal estado, 

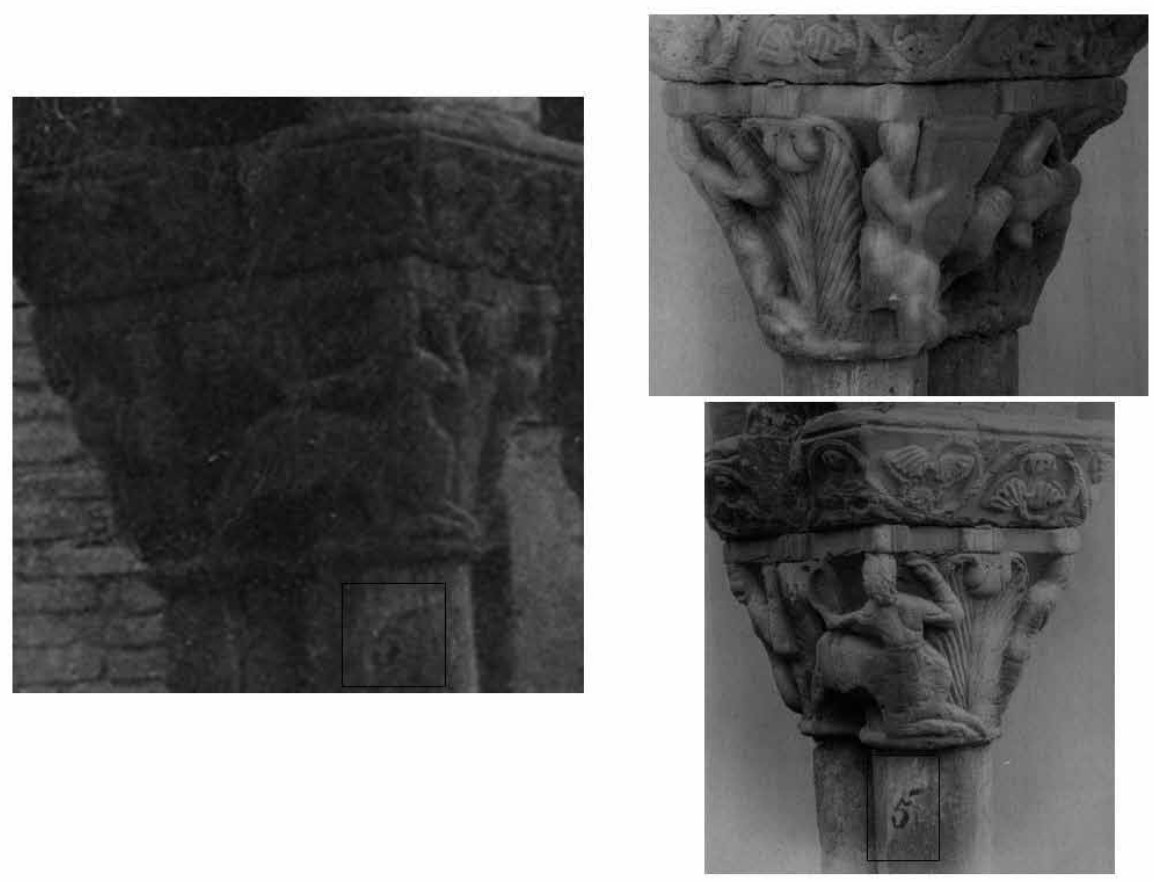

Fig. 3. Capitel 28-27 (5) del claustro de San Pedro el Viejo, Huesca, AGA 31-8060 Hojas no 6 y 15 (1888).

igual que sus originales en el Museo Provincial de Huesca, lo que dificulta el cotejo iconográfico de los mismos con su correspondiente copia actual.

Resta comprobar diez posiciones correspondientes a capiteles de las arquerías septentrional y oriental de los que no tenemos fuentes que nos proporcionen algún tipo de numeración o fotografía antigua: 5, 8, 11, 12, 13, 34, 35, 36, 37,38 . Actualmente, en esos puntos tenemos copias de las que es muy difícil verificar la fidelidad a los originales, dado que éstos, conservados en el Museo (y al parecer no todos), se encuentran en muy mal estado de conservación. De algunas de estas piezas únicamente se aporta una probable ubicación e identificación iconográfica ${ }^{26}$.

${ }^{26}$ Hay que tener en cuenta que las tres últimas posiciones se quedan "vacías" porque tres capiteles de la panda este pasan a la sur. Material utilizado para el examen de esas posiciones (además del ya reseñado que sirve de manera indirecta): las memorias de Bolomburu y Magdalena, las crónicas de Del Arco y Crozet, las fichas de registro de los capiteles originales en el Museo Provincial de Huesca (MPH), las propias cestas erosionadas, las reproducciones en piedra de Bolomburu, las copias en yeso de Magdalena y los capiteles en el claustro. Respecto a los capiteles en el Museo, he adscrito a cada uno de ellos su copia en el claustro mediante la llamada en el texto "Núm... MPH". 

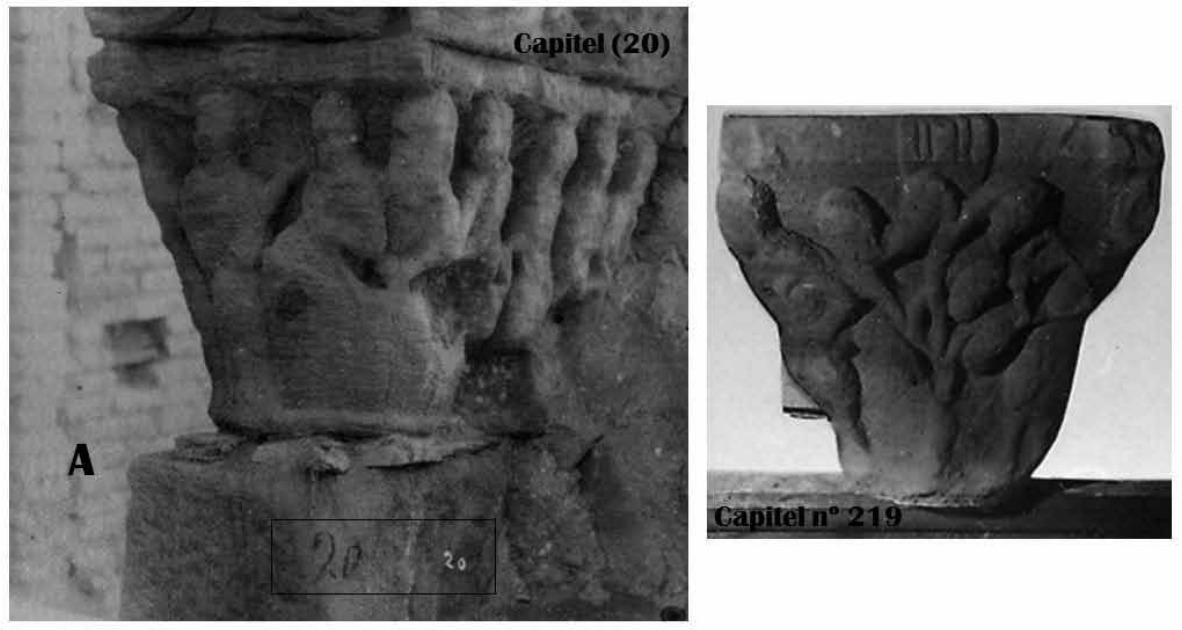

Fig. 4. Capitel (20) en el claustro de San Pedro el Viejo, Huesca, RABASF, 3-438 Hoja no 29 (1888) y capitel $n^{\circ} 219$ Inventario General del claustro de San Pedro el Viejo, Museo Arqueológico Provincial de Huesca (1918).

\section{Análisis de los capiteles ${ }^{27}$}

Como he avanzado al principio, atendiendo a toda la documentación, clasifico en seis grupos los treinta y ocho capiteles actuales, precisando su adecuación o no al claustro original.

A) Originales in situ: 31, 29, 26, 22, 15. (fig. 1, color oscuro con contorno)

Las fotos generales de las galerías meridional y occidental, así como las imágenes individuales con numeración en el fuste, permiten confirmar que Magdalena (sin que conozcamos su método ${ }^{28}$ ) recolocó este grupo de capiteles sin modificar su distribución originaria. Sin embargo, los tres primeros merecen ciertos comen$\operatorname{tarios}^{29}$.

En la foto general de 1888 (fig. 2) se observa que la arquería sur estaba truncada en el arco correspondiente al capitel que debería haberse numerado con el (3). Por otro lado, se distingue una labra sin soporte en los escombros del patio numerada con el orden (18): es la 31 actual. Finalmente, la primera serie de los capiteles fotografiados en los soportes corresponde, en la panda norte, al (17) 14 actual, saltando

\footnotetext{
27 Se aconseja reseguir este apartado con las descripciones del apéndice y figs. 1 y 2 .

28 Vid. Supra n. 23

29 Los capiteles 22-22 (9) y 15-15 (16) no comportan ningún tipo de cambio.
} 
la numeración tres posiciones sin numerar hasta el (19). Si se comprueba el programa iconográfico ( $c f$. apéndice) no tendría sentido colocar la pieza numerada como (18) entre la serie cristológica después del (17). Cabría entender por tanto que la labra no se numeró correlativamente por no conservarse en su lugar y que, al acabar una secuencia de marca de los fustes, tuvieron que incluirla con el orden $(18)^{30}$.

La estructura de ocho columnas del capitel 29 no se computa. Diversas fotos muestran claramente que su situación original es la misma que la actual, aunque se recolocó invirtiendo las caras N/S. Es decir, las representaciones de mujeres estirándose los cabellos y la pila central que contiene cinco cabecitas, aparecen en la fotografía antigua por el lado sur, mientras que hoy se emplazan en la cara norte ${ }^{31}$.

En el capitel 26-26 (6) subrayo un nuevo cambio de orientación tal como ocurre en la pieza anterior. La cara este, donde hoy se representa a un hombre que hinca con su espada la mandíbula de una bestia, en época románica estaba orientada hacia el oeste.

B) Originales cambiados de sitio: 37 en 33, 8 en 7 ( $v i d$, color oscuro sin contorno)

La fig. 2 demuestra que, antes de la restauración, en la posición 33 se hallaba el capitel 37, atisbándose en el vértice suroeste la figura de Caín o Abel. Como hemos visto, su fotografía individual indica la numeración (1) en el fuste, es decir que durante la recolocación tendrían que haberlo emplazado en la posición 33 y no en la 37 actual. Este original, igual que el capitel 38, se cambia en la restauración de la crujía sur al lado este. Para entonces, Magdalena no disponía de la numeración indicada en los soportes porque los capiteles ya se habían desmontado ( $c f$. n. 16). La razón que le lleva a colocarlos en la nueva disposición pudo haber sido considerar las piezas 37 y 38 como historiadas, y por consiguiente, solidarios con el ciclo de Cristo en la arquería este.

La posición del original 8 (Tentaciones) es más difícil de asegurar. Su foto individual (21) no aporta información al respecto (recordemos que por el momento no se ha encontrado foto general de la panda norte). De todas maneras, es probable que originariamente hubiese estado en el punto 7 por varias razones. El capitel de la Presentación 4-4 (23), según su foto individual, se localizaba sin lugar a dudas adosado al pilar noreste. Siguiendo el relato evangélico, las Tentaciones (21) se acotarían no muy lejos de ese pilar. Por otro lado, en una fotografía de 1888 el muro de contención este (figs. 2 y 4 "A") se divisa muy cercano a la labra (20). Después de ésta, le seguiría la (21). Además, en la posición 8 se apeaba uno de los contrafuertes construidos décadas antes a 1888, circunstancia que perjudicó ostensiblemente la forma de los capiteles, cosa que no se percibe en el caso del 8 , en buen estado de conservación ( $c f$. n. 12).

${ }^{30}$ Creo que este ejemplo demuestra que en época de Nicolau se numeraron las galerías meridional y occidental, contando con desmontarlas primero. Desatendida entonces la pieza 31, fue durante los trabajos de Bolomburu, cuando se numeraron las restantes y la (18) ( $c f$. n. 12 y 16).

31 Me figuro que no decidieron arrancarla en primera instancia como las otras labras, a causa de la construcción anexa de unos retretes al soporte del capitel. 
C) Piezas en el mismo sitio con la misma iconografía que los originales: copias de Magdalena 25, 24, 23, 14, 4; y restauraciones de Bolomburu 21, 20, 19, 18, 17, 16. (fig. 1, color en sombra con contorno).

A partir de las diversas fuentes gráficas, se confirma sin problemas que este grupo de cestas se recolocó en el mismo lugar. Pero como se trata de copias y piezas retocadas, se harán a continuación algunos comentarios relativos a su iconografía.

En cuanto a las copias realizadas por Magdalena, el Museo contiene los trozos de yeso que mandó trabajar el arquitecto según se lee en una de sus memorias ( $c f . \mathrm{n}$. 22). Los originales de este grupo también en el Museo se identifican sin problemas a partir de las fotografías individuales de 1888. Comparando estas fotos con los calcos hoy en el claustro, se puede afirmar que la reproducción es bastante correcta, tanto para el 25, donde se distinguen en los dos tipos de piezas el monstruo mordido por una serpiente gigante, el relieve de la cola del animal en forma de cono y el pico del ave ${ }^{32}$, como para el 24 y su pareja adosada, 23, con sendos personajes que parecen imitaciones fieles del original ${ }^{33}$.

La copia del capitel 14-14 (17) corresponde a una Crucifixión, también de Magdalena. Su original (núm. $451 \mathrm{MPH}$ ) muestra en la cara exterior una figura muy erosionada, donde en el calco se escenifica todo un cortejo de hombres. Esta Crucifixión conserva además una reproducción en piedra (núm. $456 \mathrm{MPH}$ ) que ayuda a esclarecer aquel registro degradado en el original: un personaje central enmarcado solo y supuestamente arrodillado, reconocido por Crozet como "[...] saint JeanBaptiste apparaît à mi-corps dans sa prison figurée par une construction à arcades" (p. 47). Estamos ante un primer ejemplo de lo que Bolomburu realizó como restauraciones de esculturas en sus cuatro caras, ya que el capitel es totalmente nuevo aunque copiado del original (cf. n. 13-17-18)

32 La Fundación Lázaro Galdiano guarda interesantes dibujos realizados por Vicente Carderera. En unos de estos, se aprecia la cola de la serpiente. Tal vez no sea tan trascendental este detalle, sino el hecho de que el dibujante parece respetar en gran medida la realidad formal de las figuras; CARDERERA, Vicente, "Acuarelas", Fundación Lázaro Galdiano, sign. IM 9524, 1836. Antes de ser sustituido por Magdalena, Bolomburu pudo haber tenido la intención de reproducir en piedra análoga también esta pieza, teniendo en cuenta como se verá más adelante que trabajó bastante los capiteles de esta galería. En el Museo se conserva una piedra no muy desgastada (núm. $446 \mathrm{MPH}$ ) que escenifica en un registro la lucha de un hombre de frente y dos animales que lo rodean, recordando al capitel 25. Bolomburu dice que construirá "de nuevo aquellos capiteles cuyos trazos se han perdido por completo" y prevé para "después del desmonte de los cuatro claustros [...]" realizar "esculturas en capiteles nuevos para columnas sencillas" (cf. n. 18). Asimismo, para las labras 23 y 24 es preferible analizarlas iconográficamente a partir de sus fotografías antiguas, y no desde las copias.

33 25-25 (7) (núm. $222 \mathrm{MPH}$ ), 24-24 (8) (núm. 1548 MPH), 23-23 (8) (original no conservado).

34 CROZET, René (1968), op. cit., p. 47. Magdalena, en el momento de asumir la dirección de las obras no utilizó esta copia por alguna razón que desconocemos. Podría haber sido por alguna cuestión logística, como por ejemplo que las piezas se encontrasen en un taller próximo a las obras, sin volver al claustro cuando se cambiaron los arquitectos. Aún no he podido confirmar con total certeza en las fichas, el momento en que entraron al Museo todos los objetos del claustro. 
La fotografía individual de 1888 confirma sin lugar a dudas que la labra 4 perteneciente a una posible Presentación. Iba adosada al pilar noreste ${ }^{35}$. Parece ser que Crozet vio su otra cara adosada, que se relaciona con esta escena (p. 46). Como apunté más arriba, esta pieza delimita y a su vez asegura, las posiciones de las piezas que se encuentran en los ángulos noreste, explicadas más adelante.

Los capiteles siguientes, detallados como restauraciones, parecen incluirse en la técnica de imitación directa que ejecutó Bolomburu en todas o parte de las caras de algunas labras, hoy día en la misma posición $\left(c f\right.$. n. 18) ${ }^{36}$.

En la imagen individual del capitel 21 (10) se observa el rostro erosionado de una mujer en el ángulo suroeste. Actualmente, ese rostro está perfectamente delineado. Asimismo, el capitel 18 (13) no representa en la cara frontal la mesa donde se sentarían Jesús y los apóstoles después de la Resurrección, pero sí se distingue en una acuarela de Carderera $^{37}$. En el capitel 17 (14), las figuras de Pilatos y uno de los discípulos estaban en 1888 absolutamente desgastadas, pero hoy en ese registro se distinguen los rostros bien cincelados ${ }^{38}$. La pieza 16 (15) muestra licencias artísticas como por ejemplo las formas circulares de flores que el escultor ha grabado en el sarcófago de Cristo.

D) Piezas en distinto sitio con la misma iconografía de los originales: restauraciones de Bolumburu 36 en 30, 38 en 28; copias de Bolomburu 33 en 32, 28 en 27. (fig. 1, color en sombra sin contorno).

Gracias a la foto general de 1888 (fig. 2), vemos que estos capiteles meridionales están claramente cambiados de sitio. No exigen comentarios respecto a su ubicación, pero sí a nivel formal. Las dos labras descritas a continuación muestran los mismos tipos de retoque que las del apartado anterior ( $c f$. n. 13-17-18). La foto individual del 36-30 (3) enseña las garras de uno de los animales sobre el astrágalo con unas formas distintas al capitel presente en el claustro, y por ello podría adscribirse a las esculturas restauradas por Bolomburu en dos de sus caras. En el claustro original se reconoce perfectamente el capitel 38-28 (4) con comitiva y carro,

35 4-4 (23) (núm. 460 MPH). De la crujía oriental no he localizado por el momento ningún documento fotográfico de panorámica general, únicamente un dibujo de Carderera que no permite conclusiones alentadoras; CARDERERA, Vicente (1836), op. cit., sign. IM 9759.

36 De todos modos, las comparaciones realizadas para discernir entre originales y correcciones no son definitorias, aunque cabría recordar que Del Arco ya anunciaba en 1914 que "sólo tres o cuatro capiteles son auténticos, sin adición alguna. Hay unos doce desfigurados por la restauración, y los demás son completamente nuevos"; ARCO, Ricardo del (1914), op. cit., p. 132 (la cursiva es mía).

37 CARDERERA, Vicente (1836), op. cit., sign. IM 9128.

38 Parece que está cambiado en sus caras. La foto general de 1888 está tomada desde el ángulo suroeste y la cesta no se alcanza a ver con claridad. Si observamos su posición actual, resultaría más coherente leer desde la cara norte "la petición a Herodes de soldados en el sepulcro", cara este "los soldados ante el sepulcro", cara sur "las Marías llevando perfumes" y cara oeste o interior "el ángel anunciando que Cristo ha resucitado". El dibujo de Carderera (IM 9128) muestra en la escena de la cara interior una figura en el aire que podría ser la del ángel, confirmando el cambio de orientación. 
personajes de baja estatura en la cara pequeña y columna rectangular que coincide con un plano dibujado en 1886. Atendiendo a intervenciones de la restauración de Bolomburu, parece que el escultor de esa época (que aún desconocemos) se permitió cincelar un rostro nuevo (fig. 5 "A"), el cual no vemos en el original (fig. 5 "B"); además, esculpió facciones de otro ya erosionadas (fig. 5 "C").

La pieza 28-27 (5) tal como se describe en la introducción, se recolocó en otro sitio, además con sus caras cambiadas de orientación N/S (fig. 3). Crozet se cuestiona que la pieza de la arquería actual sea un original, ya que encuentra un gran parecido con un capitel del Museo mucho menos desgastado que lo que hoy tenemos

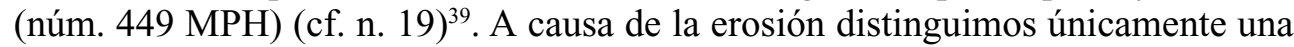
cabecita girada hacia su derecha en la esquina superior y la silueta de una figura a lo largo de otro vértice, que se podría adscribir a las formas del centauro y la bailarina, tal como anunció Crozet. Observando la foto individual de 1888, estas figuras tienen una textura desgastada y partes fracturadas que no encajan con la piedra pulida vigente. Aún más, si tenemos en cuenta que Bolomburu encarga la creación de capiteles nuevos y busca materiales análogos que no desluzcan la nueva labra,

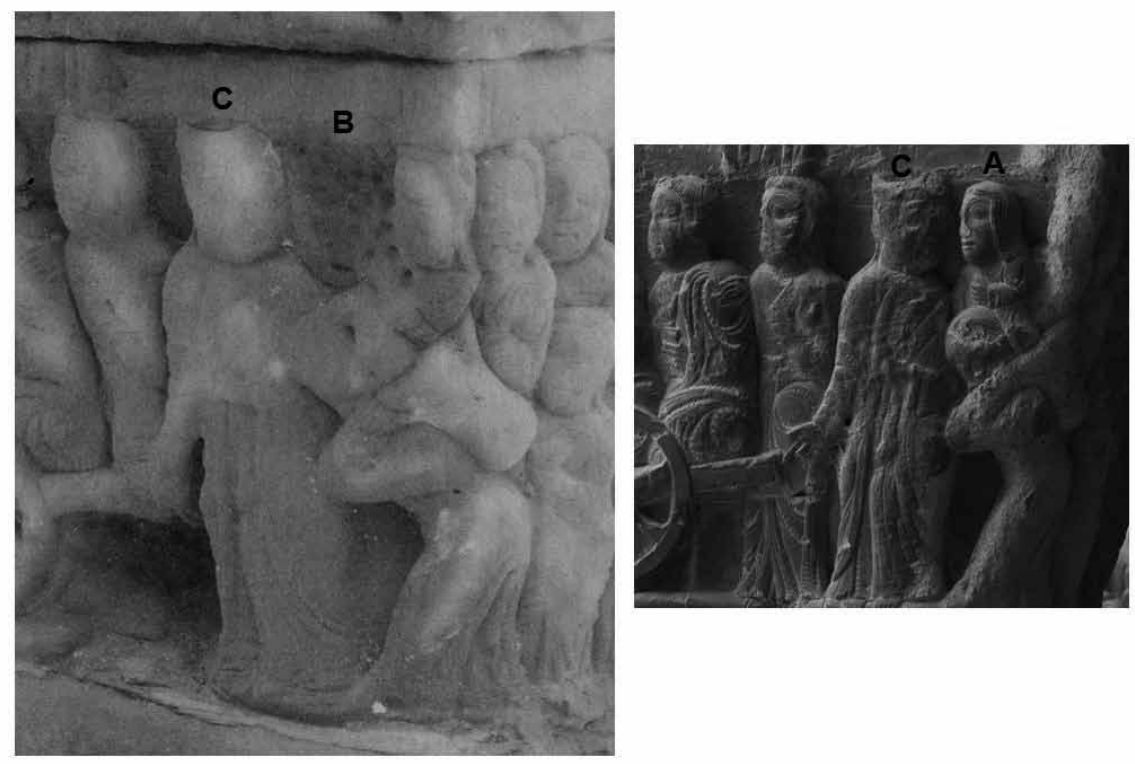

Fig. 5. Capitel 38-28 (4) en el claustro de San Pedro el Viejo, Huesca, AGA, 31-8060 Hoja no 14 (1888) e idem (2009).

39 "Un centaure sagittaire barbu décoche une flèche à une triton qui tient un poisson. Une nouvelle exploration du musée révèle un autre centaure sagittaire, imberbe cette fois, visant une femme et d'autres combats victorieux contre des monstres. Mais il y a aussi, dans le cloître, deux sirènes barbues qui se disputent une petit figure nue engage per la tête et par les pieds dans la gueule de chacun des deux monstres", CROZET, René (1968), op. cit., p. 50. 
se podría afirmar que la cesta que está hoy en la arquería es una copia del original en el Museo.

De la misma manera, la comparación entre fotografías antiguas evidencia en el 33-32 (2) la silueta de dos animales enfrentados con cabeza humana, pero vuelven a encontrarse disparidades iconográficas con la pieza del claustro actual. Existe una piedra erosionada en el museo (núm. $448 \mathrm{MPH}$ ) donde se intuyen dos masas enfrentadas acompañada de una ficha que dice "¿bestias con cabeza humana?"40. Por tanto, podríamos tener otra copia en el claustro considerada como original.

E) Copias con distinta iconografía y a las que se les puede atribuir una ubicación: 458 en 13, 440 en 12, 455 en 11,10, (20) en 9; 6 en 6,7 en 3, 3 en 2, 2 en 1 Natividad (?) (fig. 1, color claro con contorno).

De la galería meridional no contamos con fotografía general y los capiteles 13, 12 y 11 (hoy copias) no se fotografiaron individualmente en 1888. Entre los originales muy erosionados del museo no se encuentra ninguna labra con iconografía similar a la de las copias actuales, las cuales reproducen un mismo código de imágenes para las distintas caras de las tres cestas, en las que sólo cambian ciertos objetos $^{41}$. Se ha comprobado que unos originales muy degradados en el Museo sirvieron de modelos a unas labras esculpidas en una piedra cuya textura es diferente, de una porosidad más fina o regular, representando algunos pasajes de la vida de Cristo. Estas reproducciones en piedra, como pasaba en la cesta 14, podrían ser aquellas piezas que describe Magdalena refiriéndose a los trabajos de Bolomburu: "los capiteles de simple restauración [...] creyó el arquitecto encargado en aquella época que podían restaurarse los que faltaban copiando directamente los motivos de los viejos", y que el propio Bolomburu especifica en sus presupuestos ( $c f$. n. 18).

De esta manera, por alguna razón, Magdalena desecha (o no tiene a su alcance) esas reproducciones y decide seguir otro método para reproducir las copias, que son las que actualmente se encuentran en el claustro ${ }^{42}$. A través de sus memorias,

\footnotetext{
40 “Capitel N ${ }^{\circ}$ 236, Inventario de San Pedro el Viejo del Museo Arqueológico Provincial de Huesca, 1918.

41 Crozet describió "les frises" confundiendo las copias en yeso de Magdalena con los originales. Una prueba clara se observa en la numeración que asigna en su artículo a estos capiteles, los cuales son copias en yeso. Este rasgo lleva fácilmente a confusión como se lee en una ficha del capitel 14: "Vaciado de un original que representa a Jesús clavado en la Cruz". En la denominación de la materia del objeto escriben "yeso", donde alguien encima con tinta y escritura diferente corrige por "piedra", pero es yeso.

42 Detalla que "a fin de no interrumpir la marcha de las obras, hemos colocado sin labrar cinco capiteles pequeños, [...] teniendo que hacer después las esculturas y [sic] puestas en obra"; apud FONTANA CALVO, María Celia (2003), op. cit., p. 119. Las copias de los capiteles a los que hace referencia Magdalena, deduzco que serían las posiciones 13-12-11-9-6, porque las pandas sur y oeste ya estarían acabadas (las copias 27,30 y 32 ilustradas más adelante, seguramente se copiaron con facilidad tomando como modelos, labras originales de la galería meridional). Una prueba indiscutible de que Magdalena no cuidó las copias con fidelidad se lee en: "Por la índole artística del trabajo, no creemos poder llevar a efecto con buen éxito la restauración, sin proceder antes a la composición de los motivos que faltan para completar, hacer después los modelos en barro y correspondientes vaciados en yeso [...]" (cf. n. 22) (la cursiva es mía).
} 
vemos cómo el arquitecto tiene la intención de colocar secciones sin labrar, de completar composiciones y no de "copiar" un original, sino de "prueba para modelajes", como se puede constatar en la cantidad de tentativas en trozos de yeso conservados en el museo ${ }^{43}$. El recurso de Magdalena fue disponer personajes principales y secundarios con una repetición de códigos muy evidente, que desluce la riqueza iconográfica en cuanto se compara con los originales del claustro.

Todo esto parece confirmar que, según el trabajo de Bolomburu, a las tres posiciones tratadas se les puede adscribir una iconografía diferente a la actual: una última Cena, entrada a Jerusalén y muerte de Lázaro ( $c f$. n. 17). Enlazando con la cesta 14, el núm. $458 \mathrm{MPH}$ (reproducción en piedra núm. $461 \mathrm{MPH}$ ) iría situado en la posición 13 porque las caras coincidirían con el relieve de una posible mesa e incluso una figura arrodillada con aureola. A la posición 12 podría corresponderle el núm. $440 \mathrm{MPH}$, ya que se puede vislumbrar la silueta de un burrito y una figura montada. En este capitel se apeaba un contrafuerte desde hacía décadas, por lo que su original aporta muy poca información ${ }^{44}$. El capitel ubicado en 11 habría sido el núm. $455 \mathrm{MPH}$ (reproducción en piedra núm. $439 \mathrm{MPH}$ ). Muestra un entierro. En una ficha escriben "entierro de Cristo", tema que no correspondería al de Cristo porque de éste se encuentra el original in situ, en el capitel 16 $\operatorname{adosado}^{45}$.

La fotografía individual de la posición 10 (capitel central y mayor que los otros) no muestra la numeración pero parecen intuirse en el soporte de la piedra dos tipos de "19". Aceptando este número se podría seguir la correlación numérica que comienza en (1) hasta (18), saltando los tres anteriores sin numerar (seguramente porque Bolomburu consideró reproducirlos como nuevos) llegando a este $(19)^{46}$.

A la labra (20), conservada actualmente en el museo (núm. $453 \mathrm{MPH}$ ) no le corresponde ninguna copia. Este capitel iría en la posición 9, después de la 10 y correlativa a la (21). Justifico esto en lo siguiente (figs. 1, 2 y 4): por comparación de dos fotos se vislumbra la pared este "A" desde el (20). Si esta pieza hubiese

\footnotetext{
43 "[...] y que se habían trasladado al Museo más de cuarenta capiteles y molduras procedentes de San Pedro", ARCO, Ricardo del (1923), op. cit., p. 40.

${ }^{44}$ La copia actual escenifica la flagelación y el camino al Calvario, a la que se refiere Magdalena: "El trabajo para modelaje y vaciado de la prueba hecha en el capitel sencillo que representa una de las fotografías adjuntas se ha calculado [...]"; MAGDALENA, Ricardo (1890), op. cit., en Fontana, p. 124. Ficha de la copia: "Capitel N ${ }^{\circ} 223$ " Inventario General Museo Arqueológico Provincial de Huesca, 1918.

45 “Capitel № 238" Inventario General Museo Arqueológico Provincial de Huesca, 1918. Crozet se cuestiona este capitel pero no consigue establecer ninguna interpretación (p. 48).

${ }^{46} \mathrm{El}$ reconocimiento iconográfico es imposible, dado que en este elemento se alzaba otro contrafuerte ( $c f$. n. 12). Esta posición 10 habría entrado en los Presupuestos de Bolomburu como "Esculturas. En capiteles nuevos para columnas dobles" ( $c f$. n. 18), pero sin realizarse, al asumir las obras Ricardo Magdalena, quien afirma que, "A fin de no interrumpir la marcha de las obras, hemos colocado sin labrar [...] los dos mayores correspondientes a grupos de cuatro y ocho columnas teniendo que hacer después las esculturas y [sic] puestas en obra" (cf. n. 22).
} 
estado situada en la posición de los capiteles 11, 12 o 13 la foto no podría mostrar esa pared "A" porque la taparía el contrafuerte del 10. Además, se conserva mucho mejor que las labras con puntales. Exhibe en una de sus caras a Cristo con la mano alzada y a personajes dentro de un cubículo poligonal ${ }^{47}$.

Las cestas siguientes presentan muchas incertidumbres. La disposición que propongo parte del capitel (24) porque indiscutiblemente se emplazaba en el ángulo noreste, según la fotografía individual en el propio claustro de 1888. Respecto al capitel 6-6 (22), Crozet ya se plantea la originalidad de la labra: "Il s'agite d'une sculpture partiellement authentique qui a été rapiécée avec des incrustations modernes" (p. 46). Hoy en día lo que se entiende como sueño de José y Vuelta de Egipto parece bastante claro que son calcos de Magdalena ${ }^{48}$. Por otro lado, la disposición actual no guarda coherencia evangélica (la cesta además está girada), ya que escenifica el Sueño junto al Bautismo, y en el otro registro la Vuelta. La única parte que parece auténtica es el Bautismo; aceptando esto, podría concordar mejor la iconografía de la panda este que explicaré a continuación.

Recordemos que en el 4-4 (23) vemos seguramente la Presentación. La copia 7-3 (24) parece reproducir en gran medida su original en el museo (núm. 459 $\mathrm{MPH}$ ), que muestra la Matanza de los inocentes y una figura alada sobre un lecho, pero además, en la foto de 1888 se adivina una posible $\mathrm{Huida}^{49}$. En la fotografía individual de la labra 3-2 (25) se entrevé un cuadrúpedo, pudiéndose intuir esa forma en el original del museo, sumándose otro (núm. $452 \mathrm{MPH})^{50}$. Lo vinculamos a una Epifanía. Por último, en la posición 1 (hoy clara creación de Magdalena con el Matrimonio de María) calculo que iría una posible Natividad. Crozet insinúa, sin puntualizar las posiciones en sus propuestas, que tal vez la Anunciación y la Visitación representaban escenas en piezas diferenciadas. Por la fotografía individual vemos claro que la Anunciación pertenece a un (26), con su original en el museo (núm.

47 En una fotografía de archivo consta su reproducción en piedra, DURAN GUDIOL, Antonio, "Huesca y su provincia”, Guías artísticas de España, 1957, pp. 59-67. Cabe apuntar que todas estas piezas reproducidas seguramente por Bolomburu, tienen una semejanza con la iconografía de San Juan de la Peña. En otro término de cosas, a la posición 8 se le podría adscribir el último capitel erosionado que quedaba por identificar en el Museo, después de todos los cotejos realizados: se entrevé un tema historiado por la distribución de varias cabezas tocando el cimacio del capitel (núm. $443 \mathrm{MPH}$ ). En la posición 8 se apeaba un contrafuerte, y la pieza está igual de malograda y partida que la 10 y la 14 con machones.

48 De todas maneras, una fotografía individual antigua con formato diferente a las del claustro (Hoja núm. 28 AGA), muestra lo mismo, pero tal vez son incrustaciones de las que realizó Bolomburu, y después Magdalena tomó copias en yeso (conservadas en el Museo).

49 Una prueba fiable de que esta pieza se colocaba tal como presento, sería la correlación numérica de los fustes. El detalle del Sueño, se lee como otra escena de la protección del ángel al Niño, CROZET, René (1968), op. cit., p. 46. Las piezas 6 (22) y 7 (24) teniendo en cuenta el orden temático de la Vida de Cristo se encuentran hoy claramente invertidas, como ya señaló CANELLAS LÓPEZ, Ángel (1971), op. cit., p. 343.

50 Otro elemento que podría ayudar en la identificación sería un personaje del dibujo de la Fundación Galdiano que aparece sentado, como se observa en la esquina de la copia del capitel, tal vez un pastor adorando o el propio San José; CARDERERA, Vicente (1836), op. cit., sign. IM 9759. 
$454 \mathrm{MPH})$. Crozet describió una reproducción en piedra que hoy no tenemos, que muestra la Anunciación separada de la Natividad ${ }^{51}$.

F) Posiciones de las que se desconocen su iconografía y ubicación: copias de Magdalena 1, 5, 34, 35; 27, 30, $32(38,37,36)$ (fig. 1, color claro sin contorno).

De la copia 1 que escenifica los Desposorios, se conservan dos relieves en yeso y ningún original que se le pueda adscribir. Por tanto, la iconografía que vemos hoy en el claustro es muy probable que sea una creación moderna de Magdalena (cf. $n$. 42). El mismo ejemplo se podría utilizar para las copias de las posiciones 5 y $35^{52}$. La foto del AGA de la galería meridional muestra la posición 34 adosada al pilar, únicamente se aprecia la rotura en dos de la pieza (fig. 2$)^{53}$.

Nos faltan por resolver tres posiciones sin capitel, y tres copias en el claustro actual sin posición (cf. plano), pero baste decir que no creo que los calcos 27, 30 y 32 sean reproducciones de un original ${ }^{54}$. En las tres copias encontramos muchos calcos de figuración animal de la arquería meridional. Este catálogo de arquetipos puede ser de época románica, aunque Magdalena, al recolocar las piezas, entiende que los capiteles 38 y 37 son historiados, situándolos junto al ciclo de Cristo. El 36,

51 Cabría mencionar que las descripciones de Crozet con respecto a estas piezas de la Infancia mantienen muchas incongruencias, ya que no especifica si sus descripciones son de copias en yeso o de originales, que a su vez pueden ser copias en piedra de Bolomburu. Para la Natividad declara claramente la pieza realizada por Bolomburu donde "Un ange réduit à un buste ailé aux bras nus dispose avec soin une couverture sur le berceau de l'enfant où l'enfant Jésus ne repose pas encoré", y por tanto, faltaría el registro de la Natividad en sí. Además cree que el Matrimonio de María estaba destinado para capiteles adosados (quizás detalló los relieves en yeso). Esto me llevó a cuestionarme si el ciclo podía empezar en el ángulo del mediodía, hecho que creo improbable porque la foto (26) de la Anunciación muestra la estructura de un capitel doble, cerca de uno de los machones. Podría ser que se emplazase cercano al del mediodía en la posición 37 (dos fotos de 1888 demuestran que esa pieza ya no tenía los macizos y fue numerada), y para los puntos 1-38 (los más maltratados con construcciones anexas aún en 1888, sin numerar, $c f$. n. 12) no se conservasen las piezas, porque además en el Museo parecen no quedar más originales de todos los que he ido identificando. En las conclusiones se retoman estas cuestiones.

52 "A fin de no interrumpir la marcha de las obras, hemos colocado sin labrar [...] dos de ángulo" (cf. n. 41-42). Crozet describe nuevamente para la cesta 5 la copia en yeso, como se observa por la numeración que especifica de la ficha; "Capitel No 232" Inventario General Museo Arqueológico Provincial de Huesca, 1918.

53 El archivo Mas cuenta con la foto de un capitel adosado perteneciente a un pilar del ángulo sudeste con una figura humana corpulenta en el vértice, donde además se atisba una más pequeña a su lado rodeada por un árbol. Aunque la foto especifica "San Pedro el Viejo", creo que pertenece a la escena de Dios y Adán en San Juan de la Peña. Sin embargo, en otra imagen del archivo Mas que reproduce en piedra el capitel 27 (hoy copia) se distingue en un registro pequeño de la cesta la misma escena de Adán (fig. 4). Bolomburu pudo haber visto una pieza parecida a San Juan de la Peña en San Pedro y la reprodujo en una copia utilizando modelos de varias piezas para las distintas caras. También pudo haberse inspirado en capiteles de San Juan de la Peña para completar posiciones de originales perdidos, como pudo pasar en las localizaciones 11-12-13. Pero la cesta (20) demuestra que en San Juan de la Peña existen capiteles con la misma iconografía que en San Pedro.

54 La copia 27 tiene un centauro con la cabeza girada en una esquina como el 28 , un hombre clavando la espada en un animal como el 26 y el monstruo del 25. Esta pieza contiene una reproducción en piedra, seguramente de Bolomburu; "Capitel No 219” Inventario General Museo Arqueológico Provincial de Huesca, 1918. La 30 muestra escenas del 24 y 26, que a su vez se imitan en las copias de 34 y 35 . La 32 representa a dragones torciendo el cuello hacia afuera con reminiscencias de los animales del capitel 25. 
donde unos animales descarnan a otro, considera que pertenece al ciclo meridional, y lo emplaza inmediato a la esquina sureste. De esta manera, le faltaban tres posiciones en la crujía sur que adscribe a más figuración animal, sirviéndose ciertamente de modelos existentes en la misma crujía ( $c f$. n. 21-22). Magdalena tuvo muy en cuenta reforzar el mensaje visual de dicha arquería mediante el procedimiento de componer escenas semejantes a los originales de un modo tan audaz que no parece probable que sean copias de ejemplares románicos.

\section{La aproximación a un ciclo románico}

Respecto a la ubicación de los capiteles en las arquerías, gracias a la fotografía general de 1888, hemos reconocido el emplazamiento exacto de las piezas de las crujías meridional y occidental antes de la restauración. Aunque sin fuentes fiables aún, nos preguntamos hasta qué punto Magdalena reorganizó con arbitrariedad las arquerías norte y este. Respecto a la iconografía, en época de Bolomburu parte de las piezas meridionales y occidentales se modificaron formalmente en varios registros, sin que por el momento se distingan cambios sistemáticos. Más tarde, García Ocaña, el escultor contratado por Magdalena, parece recrear una realidad románica en los capiteles septentrionales, orientales y algunos meridionales, que aún no los hemos podido corregir en su totalidad por falta de documentación. No obstante, contamos en el sector noroeste con tres labras del ciclo cristológico, encargo de Bolomburu, que muestran una iconografía (parecida a San Juan de la Peña) más medieval que las copias colocadas después por Magdalena. Por último, la aportación más novedosa procede de la fotografía del capitel (20), mediante la cual hemos comprobado que existía una Vocación de Pedro hoy inexistente en la galería.

A pesar de que no hemos aclarado plenamente la posición e iconografía de las labras tal como debieron ser planteadas en su época, sí ha sido posible presentar una aproximación a la arquería románica más fiable y completa que la que teníamos hasta ahora ${ }^{55}$. En lo que concierne a las crujías sur y oeste, hemos constatado con fuentes gráficas su verdadera organización. Para la crujía norte y este nos faltan unos vacíos que se pueden examinar a partir de la referencia que hace Aynsa sobre dos ciclos antitéticos, oponiendo un relato escultórico de la Sagrada Escritura y un grupo decorativo de tipo grotesco ( $c f$. n. 7). Cabe recordar también lo que más tarde se ha observado, y es que "el carácter orgánico e integral del programa iconográfico del claustro" está dotado "de una personalidad enteriza, una e indivisa, [...] que tie-

55 Ya en el siglo XVI Aynsa contó 38 capiteles en total ( $c f$. n. 7). En 1830, los dibujos de Carderera, y en 1886 y 1888, los planos de Nicolau y Bolomburu, señalan la misma cifra. Con toda seguridad, las arquerías debían contener 38 cestas. Aynsa no especificó el número de capiteles por crujías, pero Magdalena parece seguir los planos anteriores a la restauración y las fotografías de 1888 de las galerías meridional y occidental, entendiéndose que la distribución en las otras dos mantenían el mismo trazado; $c f$. fig. 1; BOLOMBURU, Patricio, "Obras..." (1888), op. cit., Hojas n 12-35. 
ne la virtud de absorber, de conciliar en la unidad, las digresiones [...], los acentos [...] y los miniciclos [...] que sin duda contiene"

Conviene señalar que lo que se discutirá a partir de aquí no es tan sólo el orden iconográfico de cada capitel, sino también la dimensión topográfica que se establece entre las galerías, considerando las siguientes propuestas sólo como eso, sugerencias de la materia en cuestión que podrían aprovecharse en futuros estudios.

Las difíciles condiciones en que se encontraba la galería oriental no habrían permitido a Magdalena distinguir la iconografía de las cestas que faltan por identificar. Como ya he comentado, no parece probable que fueran de figuración animal. Si aceptásemos las dos labras de la Anunciación y Visitación mencionadas por Crozet tendríamos dos vacíos más completados, 37 y 38, para la Vida de Jesús, y la disposición de las arquerías cobraría un sentido más regular leyendo el ciclo narrativo desde el sitio 37 hasta su opuesto 21. La posición 36 (tal vez el $446 \mathrm{MPH}$ con figuración animal) y su pendant 22, flanqueaban el ciclo zoomorfo y psicomáquico.

En las cestas orientales 1-4 (y 38-37) podríamos contemplar la Infancia. Resulta significativo observar que la figura de la Virgen entre la posible Anunciación -37 oriental- y Asunción -21 occidental- encuadra el principio y final de la historia de la Salvación (este, norte, oeste), y a su vez, envuelve el mensaje de redención y protección contra los infortunios por acción de Satán en el ciclo contrario del Mal $(\text { sur })^{57}$. El resultado de la intervención y acción divinas para paliar los males del mundo avanza desde el Nacimiento 1 hasta la Ascensión 19. Los pasajes sucesivos de la Epifanía, Huida y Presentación 2, 3 y 4, intensificarían, con la conclusión de una etapa, el comienzo de otra en el lado norte. El Bautismo -6- iniciaría la vida adulta de Cristo, que, con gran fuerza expositiva a lo largo de toda la galería septentrional, culminaría con su Muerte en $15^{58}$.

El capitel 9 correspondería al (20) y su iconografía se podría relacionar con la vocación de san Pedro ( $M t, 14,22-23)$, que indica el comienzo de la Vida pública de Cristo, enlazando perfectamente con las Tentaciones ( 7 u 8$)^{59}$. En la imagen se aprecia a Cristo fuera de la barca y llamando ciertamente, a Pedro, lo que justificaría la elección de este pasaje con la intención de colocar al apóstol como figura destacada de alguno de los capiteles (no olvidemos la advocación del monasterio).

\footnotetext{
56 RICO CAMPS, Daniel (2004), op. cit., p. 93.

57 Asimismo, la Visitación y por tanto la concepción de san Juan el Bautista, 38, parece encontrar una respuesta más efectiva si el espectador se interesa además en su capitel opuesto, o conversión de los nuevos discípulos como mensajeros de Cristo en Pentecostés, 20.

58 Restaría por averiguar las posiciones 5 y 8 (en San Juan de la Peña encontramos las Bodas de Caná).

59 "Y Pedro respondió -Señor, si eres tú, mándame ir hacia ti sobre las aguas. Y Él dijo "Ven”. Pedro, bajando de la barca, iba caminando sobre el agua para llegar a Jesús. Pero, viendo la fuerza del viento, se atemorizó y, empezando a hundirse, dio voces, diciendo -Señor, sálvame. Al punto Jesús, extendiendo la mano, le cogió y le dijo -Hombre de poca fe, ¿por qué dudaste?"
} 
Seguidamente, la pieza 10, totalmente destruida, estaba en el centro de la arquería norte y era de estructura mayor que las restantes. La copia actual representa la Última Cena, pero por correlación con el relato evangélico tal y como lo reconstruyo en la nueva disposición no debió de ser así (la Última Cena se desplazaría a la posición del capitel 13). Quizá su iconografía original fueron los milagros de Cristo, como ocurre en una de las piezas del claustro del monasterio del que dependía San Pedro, Saint-Pons-des-Thomières ${ }^{60}$. Otra posibilidad, retomando la relación entre Cristo y Pedro, es que esta pieza 10 escenificase Mt, 16, 13-20: "Y yo te digo que tú eres Pedro, y que sobre esta piedra edificaré mi Iglesia, y las puertas del infierno no prevalecerán contra ella [...]". Hay que tener en cuenta que la estatua sobre este capitel mostraba a Pedro con las llaves y que el episodio evangélico, citado por Aynsa, se hallaba en el mismo eje que la entrada original al templo desde el claustro ${ }^{61}$.

Los capiteles 11, 12 y 13, dedicados hoy en día a extensos capítulos del Calvario, pudieron dedicarse más a la vida pública de Cristo. La labra 11 seguramente describiría la resurrección de Lázaro, hecho que desencadena la Pasión. Creo que su reproducción en piedra deja claro que una cara representa la súplica de Marta a Jesús y su opuesta el cuerpo de Lázaro muerto siendo transportado por varios personajes, uno de los cuales se intuye inclinado a causa del esfuerzo. El capitel 12 representaría la entrada a Jerusalén. El 13, la Última Cena, y como correspondería a una escenografía claustral, en una de las caras se dispondría el lavatorio o mandatum fratrum (su copia muestra una figura arrodillada con aureola frente a un grupo de figuras). Respecto al capitel 14 (Crucifixión), el último de la panda norte, quedaría por descifrar la cara sur. En la crujía occidental continúa el mensaje de Salvación que culmina con el capitel 21 (Asunción).

Al corroborar los cambios en la galería meridional (cfr. fig. 1 y apéndice), encontramos en el centro los capiteles 38 y 29 , y en los extremos de los pilares las labras 23, 24 y 37 (y seguramente 34-35) con escenas historiadas rodeadas de una figuración animal, 25, 26, 28, 36, 31 y 33 , ambas en constante lucha física y moral. Vemos cómo el maestro del claustro sabe dotar esta iconografía de una gracia especial, conseguida merced al contraste entre esas "digresiones" y "miniciclos" aún por esclarecer y los ritmos infames que dominan las figuras en el resto de las piezas.

${ }^{60}$ Capitel de Saint-Pons-des-Thomières, Multiplicación de los panes y los peces, $c a$. 1140, ahora en el Fogg Art Museum.

${ }^{61}$ AYNSA, Francisco (1619), op. cit., p. 537. Enfrentado por el sur, encontraríamos el capitel opuesto 29, que resaltaría la importancia de la reconquista cristiana de Huesca y un bautismo o entrada al seno de la Iglesia. Coronando esta pieza, probablemente se hallaba la figura de Moisés ("Fotografías, Hoja $\mathrm{N}^{\circ} 10^{\text {", }}$ AGA, 3-438, 1888). Si recapitulamos sobre lo que hemos ido comentando acerca de la conexión estratégica de diversas temáticas entre arquerías, podríamos observar un paralelismo entre Moisés y Pedro. Sería apropiado sugerir que la Antigua Ley que Dios otorgó a su pueblo a través de Moisés, se recupera de los males del mundo gracias a la Reconquista de las naciones cristianas (crujía sur), consolidándose así la Iglesia como Nueva Ley que Cristo instituyó en Pedro (crujía norte). 
El estudio sobre la restauración presentado en estas páginas ha pretendido ser un ejercicio riguroso que ayude a discernir mejor el desvirtuado programa iconográfico del claustro de San Pedro el Viejo; estudio basado en la comparación de fuentes y en el planteamiento de una labor filológica encaminada a la detección de interpolaciones artísticas. Si bien no se han podido esclarecer todas las incertidumbres que el recinto plantea, como mínimo parece posible advertir una proximidad románica más tangible.

\section{Apéndice $^{62}$}

\begin{tabular}{|c|c|}
\hline A & $\mathrm{B}$ \\
\hline $\begin{array}{l}\text { 37.- Dos personajes abrazándose. Historia de } \\
\text { Caín y Abel (originariamente en 33) }\end{array}$ & ¿Anunciación? \\
\hline $\begin{array}{l}\text { 38.- Entrada a una ciudad de un obispo en } \\
\text { carreta. Bautizo por el obispo (originariamente } \\
\text { en 28) }\end{array}$ & ¿Visitación? \\
\hline 1.- Casamiento de María y José & Natividad (MPH) \\
\hline $\begin{array}{l}\text { 2.- Anunciación. Primer Sueño de José. Nacimiento } \\
\text { de Jesús }\end{array}$ & Epifanía (MPH) \\
\hline $\begin{array}{l}\text { 3.- Adoración de los pastores. Llegada de los Reyes } \\
\text { Magos }\end{array}$ & Sueño. Huida. Matanza (MPH) \\
\hline 4.- Presentación del Niño en el templo & Presentación (MPH) (Fotografía conservada) \\
\hline 5.- Segundo sueño de José. Huida a Egipto & Posición desaparecida \\
\hline $\begin{array}{l}\text { 6.- Tercer Sueño de José. Vuelta de Egipto. Bau- } \\
\text { tismo de Cristo }\end{array}$ & Bautismo. Restaurado \\
\hline 7.- Matanza de los inocentes & Tentaciones \\
\hline 8.- Tentaciones de Cristo en el desierto & Posición desaparecida \\
\hline 9.- Entrada de Jesús en Jerusalén & $\begin{array}{l}\text { Vocación de Pedro. Conservado en el MPH. Foto- } \\
\text { grafía conservada }\end{array}$ \\
\hline 10.- Última Cena. Oración de Jesús en el Huerto & ¿Milagros de Cristo o edificación de la Iglesia? \\
\hline 11.- Prendimiento. Jesús ante Pilatos & Resurrección de Lázaro (MPH) \\
\hline $\begin{array}{l}\text { 12.- Jesús azotado en la columna. Jesús con la cruz a } \\
\text { cuestas ayudado por el Cireneo }\end{array}$ & Entrada a Jerusalén (MPH) \\
\hline 13.- Camino al Calvario de Jesús & Última Cena (MPH) \\
\hline 14.- Jesús en la cruz, a los pies las Marías y Juan & Crucifixión (MPH) \\
\hline 15.- Descendimiento & $*$ \\
\hline $\begin{array}{l}\text { 16.- Colocación de Jesús en el sepulcro. Dos ánge- } \\
\text { les turiferarios }\end{array}$ & * Restaurado \\
\hline
\end{tabular}

62 A) Propuesta actual en el claustro. B) Propuesta presentada en este artículo. En negrita: los originales. Asterisco: la misma iconografía. 


\begin{tabular}{|c|c|}
\hline $\begin{array}{l}\text { 17.- Las tres Marías con ungüentos, soldados en } \\
\text { el sepulcro }\end{array}$ & * Restaurado \\
\hline 18.- Jesús se aparece a los discípulos de Emaús & * Restaurado \\
\hline $\begin{array}{l}\text { 19.- Cena de Emaús. Duda de Tomás. Ascensión } \\
\text { de Jesús }\end{array}$ & * Restaurado \\
\hline 20.- Pentecostés. Tres personajes con cruz y un niño & * Restaurado \\
\hline 21.- Dormición & * Restaurado \\
\hline 22.- Lazos, follaje, guerreros & $*$ \\
\hline $\begin{array}{l}\text { 23.- Señor sentado en un sillón juzgando a un hom- } \\
\text { bre que está sujeto por unos guerreros }\end{array}$ & * Fotografía conservada \\
\hline 24.- Hombre recostado sobre una mujer & * (MPH) Fotografía conservada \\
\hline $\begin{array}{l}\text { 25.- Guerrero sujetando a dos dragones alados. Per- } \\
\text { sonaje atacado por un monstruo }\end{array}$ & * (MPH) Fotografía conservada \\
\hline 26.- Dragones y guerreros luchando & $*$ \\
\hline $\begin{array}{l}\text { 27.- Dragón alado luchando con centauro. Guerrero } \\
\text { y diablo luchando }\end{array}$ & $\begin{array}{l}\text { Músico con arpa y danzarina. Sirena y centauro } \\
\text { (MPH) Fotografía conservada. (Hoy 28) }\end{array}$ \\
\hline $\begin{array}{l}\text { 28.- Músico con arpa y danzarina. Sirena y cen- } \\
\text { tauro }\end{array}$ & $\begin{array}{l}\text { Entrada a una ciudad. Bautizo (Hoy 38) Restau- } \\
\text { rado }\end{array}$ \\
\hline $\begin{array}{l}\text { 29.- Rey a caballo. Toma de una ciudad. Bautizo. } \\
\text { Mujeres sufriendo }\end{array}$ & $*$ \\
\hline $\begin{array}{l}\text { 30.- Señor en la almena de un castillo. Dragones. } \\
\text { Guerreros rescatando a una doncella }\end{array}$ & Animales que devoran a otro. Restaurado (Hoy 36). \\
\hline 31.-Monstruos que succionan los senos de mujeres & * \\
\hline 32.- Animales demoníacos y guerreros & Arpías devoran a un personaje (MPH) (Hoy 33) \\
\hline 33.- Arpías devoran a un personaje. ¿Original? & $\begin{array}{l}\text { Dos personajes abrazándose. Historia de Caín y } \\
\text { Abel (Hoy 37) }\end{array}$ \\
\hline 34.- Caballos alados atacan a una mujer. Guerreros & Posición desaparecida \\
\hline $\begin{array}{l}\text { 35.- Guerreros rescatando a una mujer de unos dra- } \\
\text { gones }\end{array}$ & Posición desaparecida \\
\hline 36.- Animales que devoran a otro & $\begin{array}{l}\text { Posición desaparecida. ¿Figuración animal, } 446 \\
\text { MPH? }\end{array}$ \\
\hline
\end{tabular}

